\title{
Self-Expanding Metal Stent (SEMS): an innovative rescue therapy for refractory acute variceal bleeding
}

Authors

Institution
Kinesh Changela, Mel A. Ona, Sury Anand, Sushil Duddempudi

Department of Gastroenterology, The Brooklyn Hospital Center, New York, United States submitted

12. February 2014 accepted after revision 7. July 2014

\section{Bibliography}

DOI http://dx.doi.org/

$10.1055 / \mathrm{s}-0034-1377980$

Published online: 24.10 .2014

Endoscopy International Open

2014; 02: E244-E251

(C) Georg Thieme Verlag KG

Stuttgart · New York

E-ISSN 2196-9736

\section{Corresponding author}

Kinesh Changela, MD

Department of

Gastroenterology

The Brooklyn Hospital Center

121 DeKalb Avenue

Brooklyn

New York 11201

United States

Phone: +1-516-582-8772

Fax: +1-718-852-837

kinooo2002@gmail.com

\section{License terms}

(ब)(1) $\Theta \circledast$
Background: Acute variceal bleeding (AVB) is a life-threatening complication of liver cirrhosis or less commonly splenic vein thrombosis. Pharmacological and endoscopic interventions are cornerstones in the management of variceal bleeding but may fail in $10-15 \%$ of patients. Rescue therapy with balloon tamponade (BT) or transjugular intrahepatic portosystemic shunt (TIPS) may be required to control refractory acute variceal bleeding effectively but with some limitations. The self-expanding metal stent (SEMS) is a covered, removable tool that can be deployed in the lower esophagus under endoscopic guidance as a rescue therapy to achieve hemostasis for refractory AVB.

Aims: To evaluate the technical feasibility, efficacy, and safety of SEMS as a rescue therapy for AVB. Methods: In this review article, we have performed an extensive literature search summariz-

\section{Introduction}

$\nabla$

Acute variceal bleeding (AVB) is the most common and severe complication of liver cirrhosis. It is defined as active bleeding from esophageal and/or gastric varices seen during endoscopy or non-bleeding varices with blood in the stomach and no other source of bleeding [1]. It is associated with high inpatient mortality rates (30-50\%) [2], and accounts for $70 \%$ of all upper gastrointestinal bleeding in patients with portal hypertension [3]. Variceal bleeding is a well-known risk factor for complications such as bacterial infections, hepatic encephalopathy, hepato-renal syndrome, and decompensated liver disease. Thomopoulos et al. observed that $10.7 \%$ of patients develop recurrent bleeding during initial hospitalization and also found that the severity of liver injury (Child-Pugh C) and shock on admission were independent predictors of 6-week mortality [4]. The presence of these factors upon admission should alert physicians to provide early resuscita- ing case reports and case series describing SEMS as a rescue therapy for AVB. Indications, features, technique, deployment, success rate, limitations, and complications are discussed.

Results: At present, 103 cases have been described in the literature. Studies have reported $97.08 \%$ technical success rates in deployment of SEMS. Most of the stents were intact for 4-14 days with no major complications reported. Stent extraction had a success rate of $100 \%$. Successful hemostasis was achieved in $96 \%$ of cases with only $3.12 \%$ found to have rebleeding after placement of SEMS. Stent migration, which was the most common complication, was observed in 21 $\%$ of patients.

Conclusion: SEMS is a safe and effective alternative approach as a rescue therapy for refractory AVB.

tive measures and consider alternative approaches for management.

Over the past two decades, mortality rates have decreased significantly from $60 \%$ to $17 \%$ at 6 weeks due to recent advances in the management of variceal bleeding [5]. The principal steps in management of AVB are hemodynamic resuscitation by correcting hypovolemia, predicting and treating complications of AVB, and achieving adequate hemorrhage control. Initial resuscitation measures include airway protection by intubation, placement of large gauge IV access preferably central line, and normal saline infusion to maintain central venous pressure $[6,7]$. Although correction of coagulopathy with fresh frozen plasma (FFP) and platelets is widely practiced, there is no evidence to support this. Infection is a strong prognostic indicator and few meta-analyses have shown that short-term antibiotic prophylaxis confers a significant beneficial effect by decreasing mortality and incidence of bacterial infections [8-10]. Pharmacological therapy with vasoactive 
drugs such as terlipressin, somatostatin, octreotide, or vapreotide should be started if AVB is suspected during the pre-endoscopic setting [11-13]. Endoscopic therapy is the cornerstone for achieving adequate hemorrhage control, which should be done within 12 hours from arrival at the hospital. The success rate of endoscopic therapy is almost $90 \%$ [14]. Delaying endoscopy for more than 15 hours is a risk factor for inpatient mortality [15]. Traditionally, injection sclerotherapy with aethoxysklerol or cyanoacrylate was widely used but has been replaced with more definitive treatments such as variceal band ligation (VBL) [1]. Meta-analyses and studies have shown that a combination of endoscopic therapy and pharmacotherapy significantly achieves bleeding control but does not change mortality [16-20].

Rescue therapy is indicated when endoscopic treatment or combination treatment have failed to control bleeding. Balloon tamponade (BT), which controls bleeding in most patients by compression of bleeding varices, may be deployed as bridging rescue therapy for more definitive therapy. Surgical approaches and transjugular intrahepatic portosystemic shunt (TIPS) are other widely used rescue treatments with success rates of approximately 95\% [21]. Recent reports have suggested that SEMS is a more effective and safer alternative than BT. In this review article, we evaluate the technical feasibility and efficacy of SEMS and discuss the limitations of other rescue therapies in the management of refractory AVB.

\section{Rescue therapies \\ $\nabla$}

\section{Balloon tamponade (BT)}

First described by Westphal in 1930 [22], the principle of compression was used to develop the Sengestaken-Blakemore tube in 1950 to control refractory AVB. It remained the only available effective therapy until 1980 [23]. It is a multi-luminal plastic tube with esophageal and gastric balloons. The Minnesota-tube is a modified version with an aspiration channel above the esophageal balloon. Success rates of BT in achieving short-term hemostasis vary between $50 \%$ and $90 \%[2,23,24]$. Bleeding reportedly recurs in $50 \%$ of cases [25]. Although BT is widely available and relatively easily applied during emergent bleeding, it has several disadvantages. BT should be deployed by skilled personnel, preferably under fluoroscopic guidance, because it has been shown that the incidence of perforations increases when inserted by inexperienced staff $[26,27]$. It is associated with serious complications such as ulceration, necrosis, and esophageal rupture owing to constant inflation $[26,28]$. Because of the high risk of aspiration of gastric contents, it is advisable to proceed with BT after elective intubation. Asphyxiation due to proximal migration of the tube, a rare complication, has been observed [29]. Occlusion of the esophagus by the balloon limits oral fluid intake. Moreover, it is an unpleasant experience for the patient. Repeat endoscopic examination requires frequent removal and placement of tamponade. BT is a bridging procedure until a definitive treatment option is available. In 1957, surgical implantation of a metal cylinder in the distal esophagus was described but was not routinely used.

\section{Surgery}

Surgical procedures are less commonly used owing to advances in endoscopy and liver transplantation. Surgical intervention remains the only option for patients in whom medical and endoscopic control of bleeding cannot be achieved or if TIPS is not fea- sible because of technical problems such as portal vein thrombosis [30]. A surgical option includes esophageal staple transaction with gastroesophageal devascularization, which has a 30-day mortality of up to $80 \%$ [31]. No difference in mortality and bleeding control was found when compared with sclerotherapy [32, 33]. Selective shunts (e.g. spleno-renal) and non-selective shunts such as small diameter porto-caval shunts are other surgical options. Spleno-renal shunts are more effective than porto-caval shunts but the latter have a lower incidence of encephalopathy and rebleeding $[34,35]$.

\section{Transjugular intrahepatic portosystemic shunt (TIPS)}

TIPS has emerged as a promising rescue therapy and offers an effective alternative to shunt surgery. It is a technically challenging procedure done at tertiary care centers that requires placement of a stent between the hepatic vein and portal vein under radiological guidance. Placement is even more difficult in the setting of portal vein thrombosis. Indications for TIPS are refractory AVB or bleeding that recurs after initial hemostasis with endoscopic therapy. The success rate of TIPS in effectively controlling AVB is $93-95 \%$ [36]. Rebleeding was observed in only $15-18 \%$ after initial intervention with TIPS - a much lower rate compared to the surgical approach. The most common and expected side effect is deterioration of hepatic function and subsequent development of hepatic encephalopathy in $35-40 \%$ patients [37].

Owing to considerable limitations of the above mentioned rescue therapies, there have been a plethora of ongoing research studies and clinical trials to develop a definitive tool for managing refractory AVB. These have led to the development of a specialized SEMS.

\section{Self-expandable metal stent (SEMS)}

The self-expanding metal stent (SEMS) is a removable, covered, self-expanding metal stent that can be deployed endoscopically with a guidewire. Initial use of SEMS was described in 1980 as a palliative treatment for malignant strictures, malignant tumors, and fistulas. Its observed effectiveness led to advances in the design and incorporation into instruments to be used as a rescue therapy for AVB. Advantages include ease of stent placement and removal without the need for radiological guidance making it a more practical therapeutic bridging intervention to stabilize a bleeding patient. We have reviewed two case reports and seven case series to evaluate the technical feasibility, safety, efficacy, and stent-related complications before and after removal of SEMS in the management of refractory AVB.

\section{Materials and methods \\ $\nabla$}

We performed an extensive English language literature search using Pubmed, Medline, and Google Scholar to identify peer-reviewed articles using the following key words: self-expandable metal stent, SEMS, and refractory acute variceal bleeding. Only articles involving human studies were selected. Search results yielded mostly small sample-sized retrospective studies including case reports and case series. The relevant studies were identified by manual search and were included as references. The indications, procedural details, technical and clinical success rates, complications, and limitations were reviewed in detail. None of the authors have any conflicts of interest or financial relationships with the company that produces or distributes the device described in the review article. 
Table 1 Patients' baseline characteristics and demographic information.

\begin{tabular}{|c|c|c|c|c|c|c|c|c|}
\hline $\begin{array}{l}\text { Author (year) } \\
\text { Location [Ref.] }\end{array}$ & $\begin{array}{l}\text { Total } \\
\text { patients }\end{array}$ & $\operatorname{Sex}(M / F)$ & $\begin{array}{l}\text { Mean age } \\
\text { (years) }\end{array}$ & $\begin{array}{l}\text { Etiology of liver } \\
\text { diseases }\end{array}$ & $\begin{array}{l}\text { Child-Pugh } \\
\text { score }\end{array}$ & MELD & $\begin{array}{l}\text { Prior bleeding } \\
\text { episodes }\end{array}$ & $\begin{array}{l}\text { Previous } \\
\text { treatments }\end{array}$ \\
\hline $\begin{array}{l}\text { Hubmann et al. } \\
\text { (2006) Austria } \\
{[38]}\end{array}$ & 20 & $18 / 2$ & 52 & $\begin{array}{l}\text { Alcoholic: } 12 \\
\text { Cryptogenic: } 4 \\
\text { Viral: } 3 \\
\text { Immunogenic: } 1\end{array}$ & B: $8, C: 12$ & Not mentioned & $\begin{array}{l}\text { Mean } 2.4 \\
\text { ( } 1-5 \text { episodes) }\end{array}$ & $\begin{array}{l}\text { BT: } 6 \\
\text { VBL: } 18 \\
\text { ST: } 5\end{array}$ \\
\hline $\begin{array}{l}\text { Matull et al. } \\
\text { (2008) United } \\
\text { Kingdom [39] }\end{array}$ & 1 & $1 / 0$ & 44 & Alcoholic: 1 & Not mentioned & Not mentioned & 1 episode & VBL \& BT \\
\hline $\begin{array}{l}\text { Zehetner et al. } \\
\text { (2008) Austria } \\
{[40]}\end{array}$ & 34 & $33 / 1$ & 56 & $\begin{array}{l}\text { Alcoholic: } 26 \\
\text { Cryptogenic: } 4 \\
\text { Viral: } 4\end{array}$ & B: $13, C: 21$ & Not mentioned & $\begin{array}{l}\text { Mean } 1 \\
\text { (0-5 episodes) }\end{array}$ & VBL: 21 \\
\hline $\begin{array}{l}\text { Dechene et al. } \\
\text { (2009) Germany } \\
{[41]}\end{array}$ & 1 & $1 / 0$ & 59 & $\begin{array}{l}\text { Portal vein thrombo- } \\
\text { sis: } 1\end{array}$ & Not mentioned & Not mentioned & None & VBL: 1 \\
\hline $\begin{array}{l}\text { Wright et al. } \\
\text { (2010) United } \\
\text { Kingdom [42] }\end{array}$ & 10 & $9 / 1$ & 49.4 & $\begin{array}{l}\text { Alcoholic: } 6 \\
\text { Viral: } 2 \\
\text { Cryptogenic: } 1 \\
\text { PBC: } 1\end{array}$ & Not mentioned & Mean: 32 & $1-2$ episodes & $\begin{array}{l}\text { VBL: } 5 \\
\text { BT: } 1\end{array}$ \\
\hline $\begin{array}{l}\text { Mishin et al. } \\
\text { (2010) Moldova } \\
{[43]}\end{array}$ & 1 & $1 / 0$ & 49 & Viral: 1 & $C: 1$ & Not mentioned & 2 episodes & VBL: 3 \\
\hline $\begin{array}{l}\text { Dechêne et al. } \\
\text { (2012) Germany } \\
{[44]}\end{array}$ & 8 & $6 / 2$ & 63 & $\begin{array}{l}\text { Alcoholic: } 3 \\
\text { Viral: } 3 \\
\text { NASH: } 2\end{array}$ & C: 8 & 29.37 & $1-6$ episodes & $\begin{array}{l}\text { ST: } 2 \\
\text { VBL: } 8 \\
\text { BT: } 2\end{array}$ \\
\hline $\begin{array}{l}\text { Holster et al. } \\
\text { (2013) The } \\
\text { Netherlands [45] }\end{array}$ & 5 & $3 / 2$ & 58 & $\begin{array}{l}\text { Alcoholic: } 3 \\
\text { Immunologic: } 1 \\
\text { Non-cirrhotic portal } \\
\text { HTN: } 1\end{array}$ & $\begin{array}{l}\text { B: } 1 \\
\text { C: } 1\end{array}$ & Not mentioned & $1-2$ episodes & VBL: 5 \\
\hline $\begin{array}{l}\text { Fierz et al. (2013) } \\
\text { Switzerland [46] }\end{array}$ & 7 & $5 / 2$ & 56 & $\begin{array}{l}\text { Alcoholic: } 4 \\
\text { Viral: } 3\end{array}$ & B: $2, C: 5$ & 27 & Not mentioned & $\begin{array}{l}\text { VBL: } 6 \\
\text { ST: } 2\end{array}$ \\
\hline $\begin{array}{l}\text { Zakaria et al. } \\
\text { (2013) Egypt } \\
\text { [47] }\end{array}$ & 16 & $14 / 2$ & 57 & Viral: 16 & A: $2, B: 8, C: 6$ & Not mentioned & Mean 0.75 & $\begin{array}{l}\text { Not } \\
\text { mentioned }\end{array}$ \\
\hline
\end{tabular}

MELD, Model For End-stage Liver Disease; BT, balloon tamponade; VBL, variceal band ligation; ST, sclerosing therapy; PBC, primary biliary cirrhosis; NASH, non-alcoholic steatohepatitis; HTN, hypertension.

\section{Results}

Ten original published articles were considered appropriate for inclusion in our review article. Of these, seven were case series from Austria [38, 40], United Kingdom [42], Egypt [47], Germany [44], Netherlands [45], and Switzerland [46]. Three case reports were from the United Kingdom [39], Moldova [43], and Germany [41]. The first case series was reported by Hubmann et al. in 2006 from Austria [38]. In total, 103 cases were reviewed from case reports and case series. All cases are summarized in $\bullet$ Table 1 and - Table 2.

\section{Demographics}

As mentioned in Table 1, most of the cases were reported from European countries. An extensive literature review revealed no published experience of SEMS in the United States because it is not FDA-approved. Of the 103 cases, 91 were men and 17 were women. Most of the reported cases involved middle aged patients. Mean age calculated from all reported cases was 54.3 years.

\section{Patients' characteristics}

Current available literature proposes that SEMS is indicated as a rescue therapy until more definitive therapy is available for AVB [38-49]. In total, 55 cases reported alcoholic cirrhosis as an un- derlying cause of acute variceal bleeding, which constitutes almost half of the total cases ( Table 1). Matull et al. describe a patient with alcoholic cirrhosis who had bleeding from varices as the result of a tear from prior BT treatment [39]. Dechene et al. deployed SEMS in a patient who had variceal bleeding owing to cirrhosis secondary to portal vein thrombosis [41]. It has been reported that VBL is a very safe and effective approach in the management of AVB [50]. Mishin et al. reported successful hemostasis of a post-VBL bleeding ulcer, which is a very rare cause of bleeding [43]. Nonalcoholic steatohepatitis (NASH) is an emerging cause of cirrhosis and its incidence is growing in recent years, which can manifest in later stage as a life-threatening variceal bleed. Dechêne et al. demonstrated the effectiveness of SEMS in two patients with NASH [44]. Holster et al. also tested the yield of SEMS in a non-cirrhotic patient who had portal hypertension secondary to liver metastasis [45]. A recent case series by Zakaria et al. described the use of SEMS solely in patients with cirrhosis secondary to hepatitis C [47]. As stated in Table 1, few authors have described the severity of liver disease in terms of ChildPugh score (CPS) and Model for End-stage Liver Disease (MELD) score. In total, 48 patients were reported to have CPS class $\mathrm{C}$ and 32 were CPS class B. Wright et al., Fierz et al., and Dechêne et al. reported mean MELD scores of 32,27 , and 29.37, respectively $[42,44,46]$. 


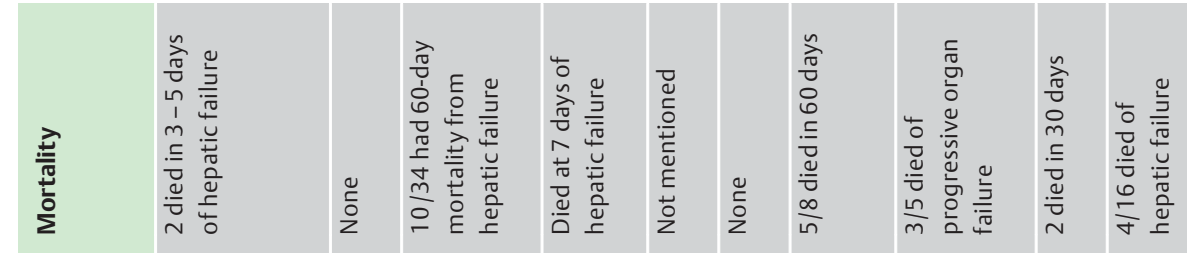

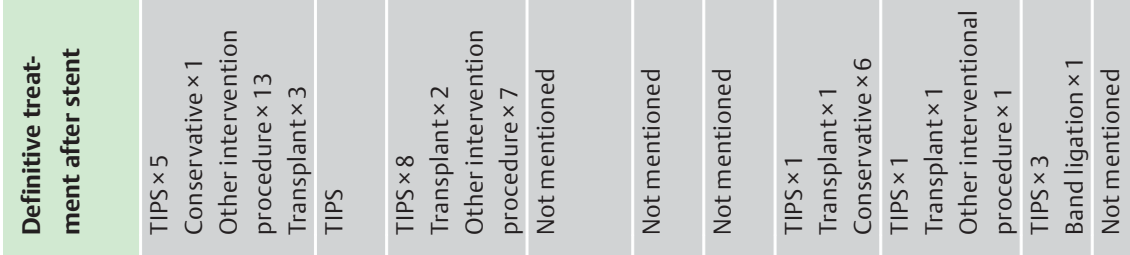

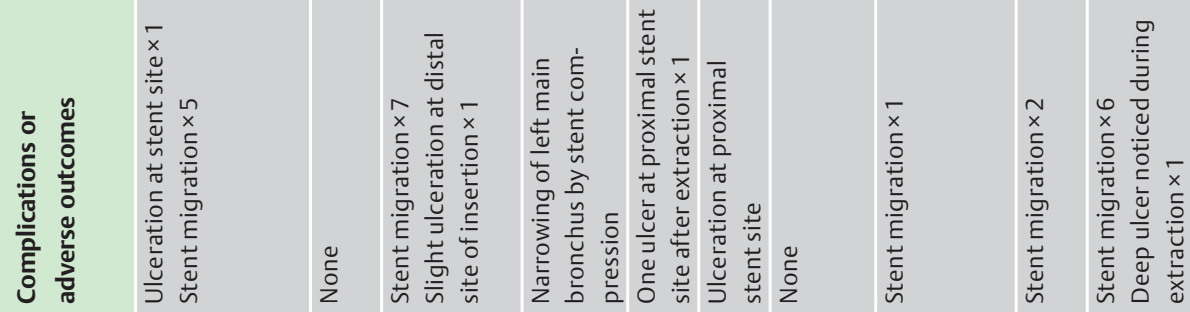

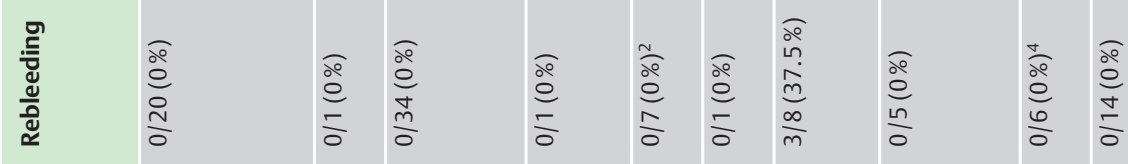

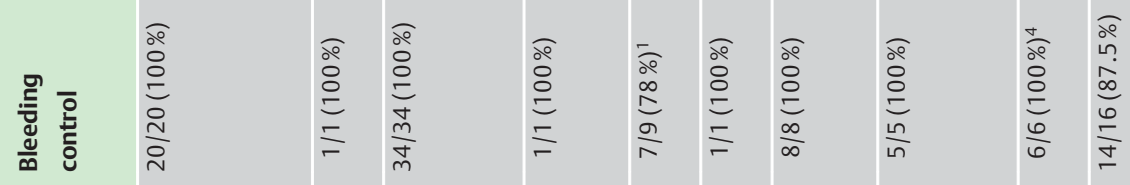

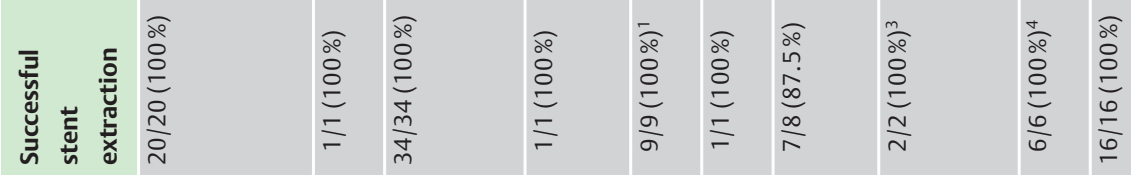

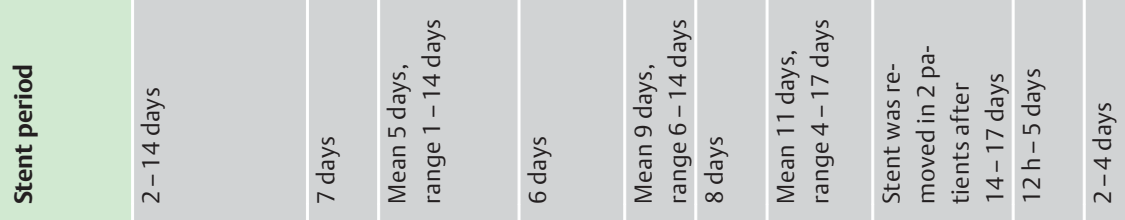

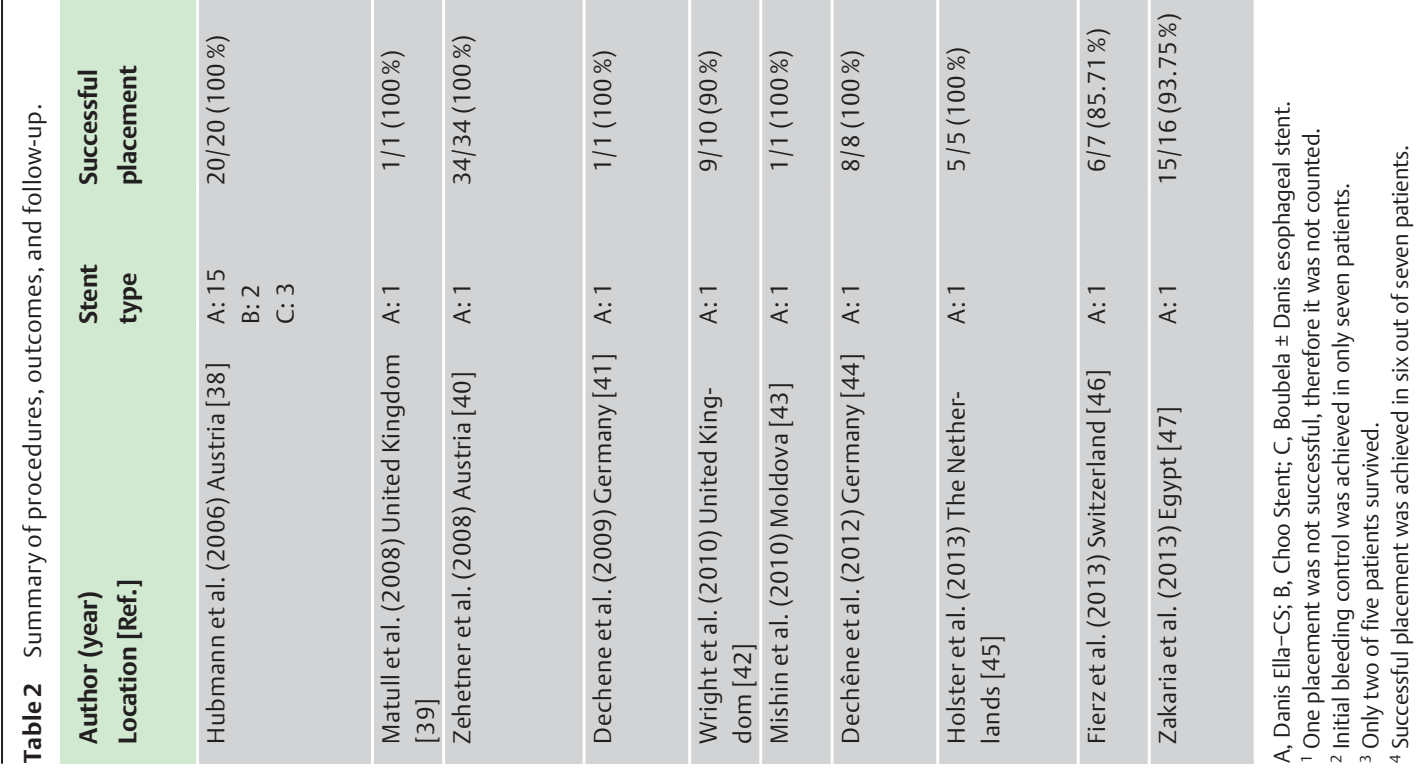




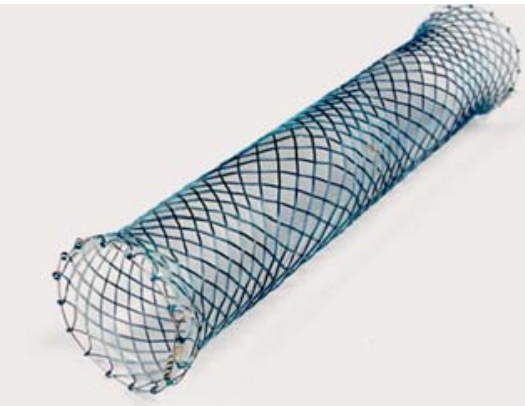

Fig. 1 Photograph of SX-Ella Danis stent with diameter of $25 \mathrm{~mm}$ and length of $135 \mathrm{~mm}$. Image reproduced with reprint permission from the manufacturer's site ELLA-CS, Hradec-Kralove, Czech Republic

The number of prior bleeding episodes before SEMS application has been described in $\bullet$ Table 1 . In most of the cases, SEMS was deployed after 1-6 episodes of bleeding, however, Dechêne et al. initiated SEMS during the first bleeding episode. All previous bleeding episodes were treated with different modalities such as BT, VBL, and sclerosing therapy (ST) ( Table 1). Placement of SEMS is contraindicated in patients with esophageal strictures and recent esophageal radiation exposure because of technical difficulty in deployment and risk of perforation, respectively. Furthermore, the use of this device for patients with tumors of the upper respiratory or gastrointestinal tract must be considered with caution.

\section{Basic features of the SEMS}

Hubmann et al. described their experience with three different types of SEMS: Danis Ella-CS, Choo Stent, and the Boubela \pm Danis esophageal stent [38]. Danis Ella-CS stents were used for the other remaining cases. SEMS is made of a nitinol stent covered with polyurethane foil with a relaxed diameter of $25 \mathrm{~mm}$ [47]. Stent length measures $135 \mathrm{~mm}$, which avoids excessive tension to the aortic arch by the proximal end of the stent. The shape of the stent matches the anatomical configuration of the distal end

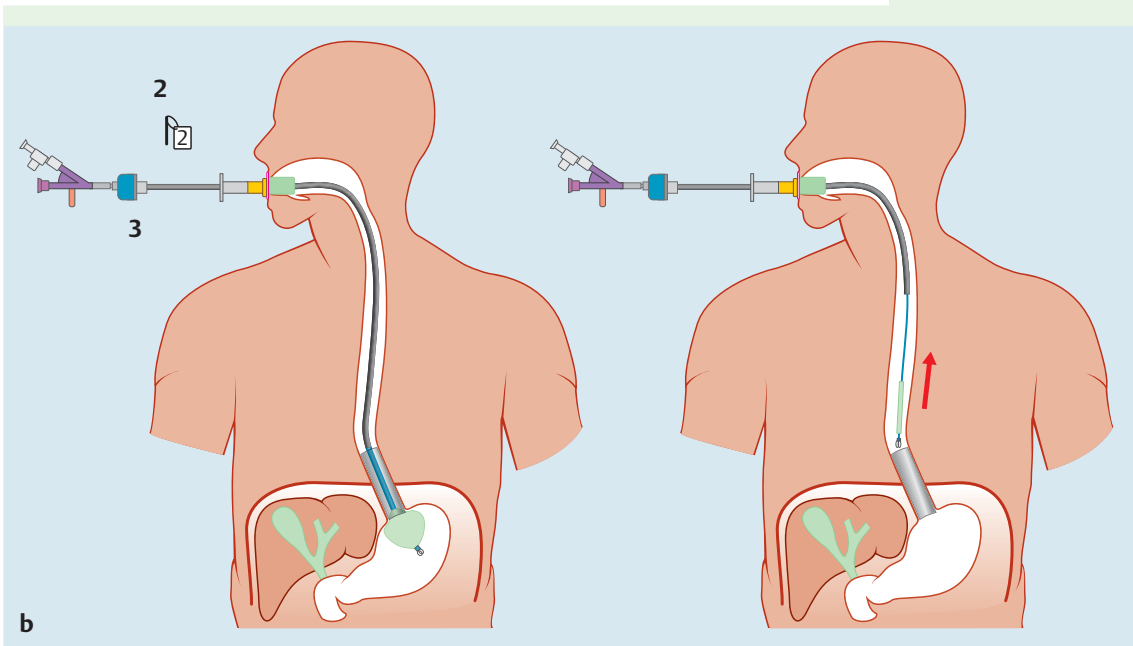

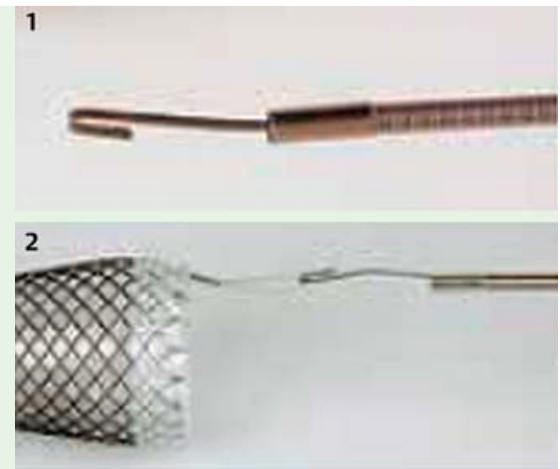
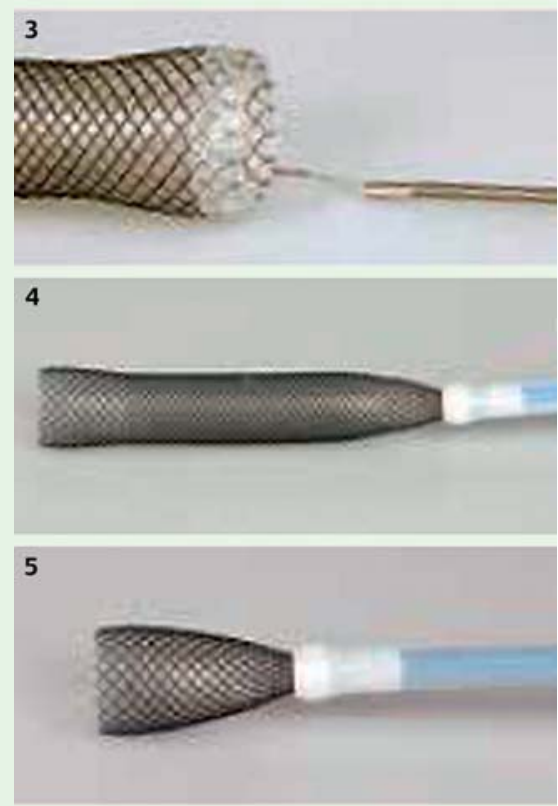

6

Fig. 2 a Photograph showing Stepwise approach of stent deployment. The stent delivery device is passed over the guidewire into the stomach which was placed under direct supervision during upper endoscopy. The gastric balloon is inflated with air. The whole delivery system is withdrawn until resistance is encountered. The stent is then deployed at the distal esophagus. b Photograph showing Stepwise approach of stent extraction. A retrieval loop at the top of the stent is captured by a hook at the end of a guidewire. A plastic sheath is advanced over the guidewire until the whole stent can be fully captured in the sheath. Images reproduced with reprint permission from the manufacturer's site ELLA-CS, Hradec-Kralove, Czech Republic. 


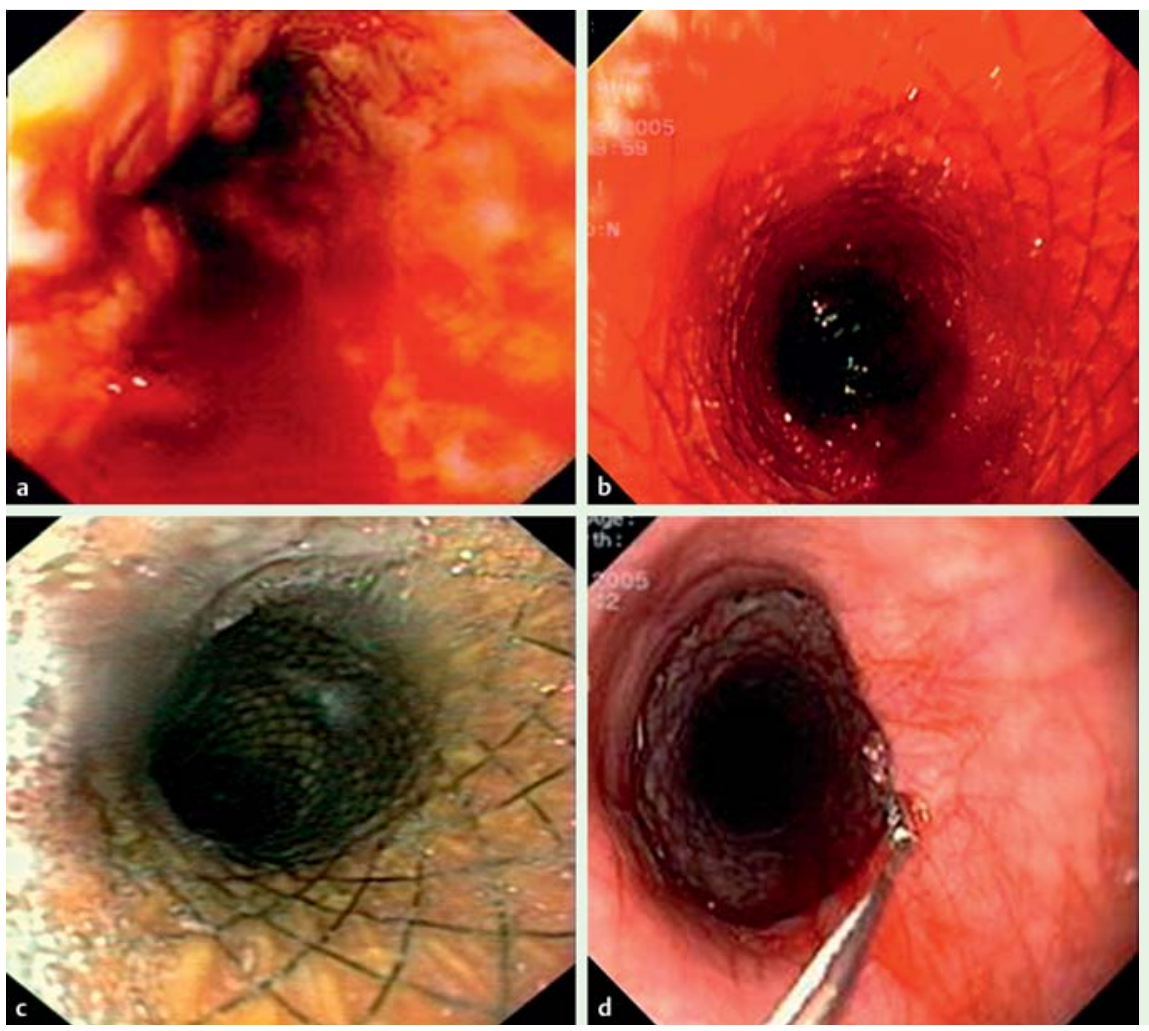

Fig. 3 a Endoscopic view of actively bleeding esophageal varices. $\mathbf{b}$ Endoscopic view of self-expanding metal stent (SEMS) directly after stent implantation. c Endoscopic view of distal esophagus with SEMS causing compression of varices leading to bleeding control. $\mathbf{d}$ Endoscopic view of the distal end of esophagus showing proximal part of stent with extraction loop. Images reproduced with reprint permission from the manufacturer's site ELLA-CS, Hradec-Kralove, Czech Republic.

of the esophagus and allows elongation and narrowing of the stent. Variable pitches in the stent braiding conform to esophageal peristalsis and reduce the risk of stent migration. There are retrieval loops at each end, which help to reposition or remove the stent. Proper marking on the delivery device guarantees correct positioning of the stent. There are radiopaque markers at both ends and at the midpoint of SEMS ( $\bullet$ Fig. 1 ).

\section{Technique \\ $\nabla$}

The technique for SEMS insertion and removal is comparatively safe. While it does not require radiological guidance, it requires some degree of expertise. First, a guidewire is inserted into the stomach under direct visualization with conscious sedation during upper endoscopy. Next, the stent delivery device is passed over the guidewire into the stomach. The gastric balloon is inflated with air and the whole delivery system is withdrawn until resistance is felt, which ensures that the balloon is impacting against the cardia of the stomach. The stent is then deployed at the distal esophagus followed by careful endoscopic examination to ensure proper stent placement and cessation of bleeding ( $\bullet$ Fig. 2 a). SEMS can remain intact for 2 days to 2 weeks to allow liver recovery. SEMS can be safely removed with a PEX-Ella extractor (Ella-CS) under endoscopic guidance. A retrieval loop at the top of the stent is captured by a hook at the end of a guidewire. A plastic sheath is advanced over the guidewire until the whole stent can be fully captured in the sheath $($ Fig. 2 b). The PEX-Ella extractor is then removed and careful endoscopic examination is performed for assessment of rebleeding and the need for further endoscopic treatment $[42,47]$. $\bullet$ Fig. 3 shows endoscopic images of stent insertion and removal.

\section{Successful placement}

SEMS was successfully deployed in 100 out of 103 cases: a $97.08 \%$ success rate. Wright et al. had one failure of stent deployment because of failure of gastric balloon deflation [42]. Zakaria et al. described a case of failure and three cases of technical difficulty during stent placement [47]. The following technical difficulties have been reported: bending of the guidewire, migration of the stent into the stomach, and malfunction of the delivery system causing rupture of the gastric balloon [47]. Stents remained safely intact for 4 to 14 days in most cases. Holster et al. kept the stent in place in three patients for between 6 and 214 days. All three patients eventually died due to progressive hepatic failure [45].

\section{Successful extraction}

Successful SEMS extraction was performed in all 96 cases with the PEX-Ella extractor (Ella-CS) under endoscopic guidance without any reported technical difficulty. Thus, SEMS extraction had a success rate of $100 \%$. A total of 100 patients had successful SEMS placement, however, four patients died before the stent was removed $[44,45]$.

\section{Successful hemostasis}

In all cases, proper stent placement and cessation of bleeding were confirmed by upper endoscopy. Of the total of 100 patients who had successful stent placement, 96 patients had immediate hemostasis achieved after stent deployment. Wright et al. found that two of the failed hemostasis cases were bleeding from gastric varices, which were confirmed on subsequent upper endoscopy. Initial endoscopy could not be performed in these cases because of the acuity of the patients' conditions and severity of bleeding. This underscores the importance of upper endoscopy to ascertain the source of bleeding before stent deployment [42]. Zakaria et al. described two cases of bleeding control failure: the first case was because of rupture of the gastric balloon, and the 
second case was because of bleeding from a small junctional varix [47].

\section{Rebleeding}

Out of 96 patients who had documented successful hemostasis achieved on primary upper endoscopy, only three patients (3.12\%) rebled. Dechêne et al. observed that the patients who had rebleeding episodes were only treated with pharmacological measures to reduce portal hypertension rather than more definitive measures such as TIPS [44]. Rebleeding rates can be decreased by more definitive treatment.

\section{Definitive treatment after stenting}

Most patients underwent more definitive treatments such as TIPS, VBL, radiological intervention procedures, and liver transplant. Few patients were treated more conservatively with pharmacological measures but it has been observed that there is a high risk of rebleeding compared to patients treated with more definitive measures.

\section{Complications, adverse outcomes and mortality}

A current review of the literature reveals that the SEMS procedure can be safely performed without any major reported complications or adverse outcomes. Stent migration into the stomach is the most commonly reported complication and was observed in 21 out of 100 successfully stented patients. Holster et al. postulated that blind insertion of a nasogastric tube may induce stent migration distally into the stomach [45]. Zakaria et al. suggested that delaying confirmatory endoscopy for 5 minutes after deployment of SEMS will allow it to fully expand and thus decrease the chances of stent migration [47]. Interestingly, none of the patients with stent migration had rebleeding. The second most common complication observed was ulceration at the stent site varying from superficial ulcerations to deep ulcerations. A total of five patients were reported to have ulceration at the site of the stent, which was noted during extraction. All of them were managed conservatively by proton pump inhibitor. Dechene et al. reported a case of narrowing of the left main bronchus by stent compression, which is very rare, but with few reported cases [41, $53,54]$. A total of 27 patients died between 7 and 60 days, mostly due to progressive hepatic damage and multi-organ failure.

\section{Summary and future directions}

Refractory AVB is a life-threatening consequence of liver cirrhosis. BT, TIPS, and surgery are proven and currently available tools to arrest uncontrollable bleeding with individual limitations. Our current literature review suggests that SEMS is an innovative therapeutic approach for refractory AVB with excellent efficacy, safety, and relatively few adverse outcomes. However, several unanswered questions remain with regard to its application as a standardized recommendation for patients. It is unclear whether SEMS is an effective option for a patient who cannot receive a more definitive approach such as TIPS, liver transplant, or surgery. There is paucity of experience with SEMS reported apart from in Europe and some parts of Russia, and it has yet to be FDA-approved in the United States. Its yield in elderly patients with multiple comorbidities must also be investigated. The role of SEMS is yet undefined in controlling gastric and junctional variceal bleed. Modifications in stent design may be warranted to overcome incidences of stent migration. At present, there are a limited number of SEMS cases reported, however, they describe significant outcomes and challenges for clinicians. Future largescale studies are needed to confirm these initial findings of SEMS as a promising tool in the control of refractory AVB.

\section{Competing interests: None}

\section{References}

1 Biecker E. Portal hypertension and gastrointestinal bleeding: diagnosis, prevention and management. World J Gastroenterol 2013; 19 : $5035-5050$

2 D'Amico G, Pagliaro L, Bosch J. The treatment of portal hypertension: a meta-analytic review. Hepatology 1995; 22: 332-354

3 D'Amico G, De Franchis R. Cooperative Study Group. Upper digestive bleeding in cirrhosis. Post-therapeutic outcome and prognostic indicators. Hepatology 2003; 38: 599-612

4 Thomopoulos K, Theocharis G, Mimidis K et al. Improved survival of patients presenting with acute variceal bleeding. Prognostic indicators of short- and long-term mortality. Dig Liver Dis 2006; 38: 899-904

5 Chalasani N, Kahi C, Francois $F$ et al. Improved patient survival after acute variceal bleeding: a multicenter, cohort study. Am J Gastroenterol 2003; 98: 653-659

6 Vlavianos P, Mac Mathuna P, Williams R et al. Splanchnic and systemic haemodynamic response to volume changes in patients with cirrhosis and portal hypertension. Clin Sci (Lond) 1999; 96: 475-481

7 Kravetz D, Bosch J, Arderiu M et al. Hemodynamic effects of blood volume restitution following a hemorrhage in rats with portal hypertension due to cirrhosis of the liver: influence of the extent of portal-systemic shunting. Hepatology 1989; 9: 808-814

8 Ferguson JW, Tripathi D, Hayes PC. Review article: the management of acute variceal bleeding. Aliment Pharmacol Ther 2003; 18: 253-262

9 Bernard B, Grangé JD, Khac EN et al. Antibiotic prophylaxis for the prevention of bacterial infections in cirrhotic patients with gastrointestinal bleeding: a meta-analysis. Hepatology 1999; 29: 1655-1661

10 Soares-Weiser K, Brezis M, Tur-Kaspa R et al. Antibiotic prophylaxis for cirrhotic patients with gastrointestinal bleeding. Cochrane Database Syst Rev 2002; 2: CD002907

11 Levacher S, Letoumelin P, Pateron D et al. Early administration of terlipressin plus glyceryl trinitrate to control active upper gastrointestinal bleeding in cirrhotic patients. Lancet 1995; 346: 865-868

12 Calès $P$, Masliah C, Bernard $B$ et al. Early administration of vapreotide for variceal bleeding in patients with cirrhosis. N Engl J Med 2001; 344: $23-28$

13 Avgerinos A, Nevens F, Raptis $S$ et al. Early administration of somatostatin and efficacy of sclerotherapy in acute oesophageal variceal bleeds: the European Acute Bleeding Oesophageal Variceal Episodes (ABOVE) randomized trial. Lancet 1997; $350: 1495-1499$

14 Lo GH, Lai KH, Ng WW et al. Injection sclerotherapy preceded by esophageal tamponade versus immediate sclerotherapy in arresting active variceal bleeding: a prospective randomized trial. Gastrointest Endosc 1992; 38: 421 - 424

15 Hsu YC, Chung CS, Tseng CH et al. Delayed endoscopy as a risk factor for in-hospital mortality in cirrhotic patients with acute variceal hemorrhage. J Gastroenterol Hepatol 2009; 24: 1294-1299

16 Sung JJ, Chung SC, Yung MYet al. Prospective randomised study of effect of octreotide on rebleeding from oesophageal varices after endoscopic ligation. Lancet 1995; $346: 1666-1669$

17 Bañares R, Albillos A, Rincón D et al. Endoscopic treatment versus endoscopic plus pharmacologic treatment for acute variceal bleeding: a meta-analysis. Hepatology 2002; 35: 609-615

18 Besson I, Ingrand P, Person B et al. Sclerotherapy with or without octreotide for acute variceal bleeding. N Engl J Med 1995; 333: 555-560

19 Zuberi BF, Baloch Q. Comparison of endoscopic variceal sclerotherapy alone and in combination with octreotide in controlling acute variceal hemorrhage and early rebleeding in patients with low-risk cirrhosis. Am J Gastroenterol 2000; 95: 768-771

20 D'Amico G, Pietrosi G, Tarantino I et al. Emergency sclerotherapy versus vasoactive drugs for variceal bleeding in cirrhosis: a Cochrane meta-analysis. Gastroenterology 2003; 124: 1277-1291

21 Boyer TD, Henderson JM, Heerey AM. DIVERT Study Group. et al. Cost of preventing variceal rebleeding with transjugular intrahepatic portal systemic shunt and distal splenorenal shunt. J Hepatol 2008; 48: $407-414$ 
22 Sengstaken RW, Blakemore AH. Balloon tamponade for the control of hemorrhage from esophageal varices. Ann Surg 1950; 131: 781 - 789

23 Panés J, Terés J, Bosch J et al. Efficacy of balloon tamponade in treatment of bleeding gastric and esophageal varices. Results in 151 consecutive episodes. Dig Dis Sci 1988; 33: 454-459

24 Jaramillo JL, de la Mata M, Miño G et al. Somatostatin versus Sengstaken balloon tamponade for primary haemostasis of bleeding esophageal varices. A randomized pilot study. J Hepatol 1991; 12: 100-105

25 Bosch J, Berzigotti A, Garcia-Pagan JC et al. The management of portal hypertension: rational basis, available treatments and future options. J Hepatol 2008; 48: 0168 -S92

26 Chojkier M, Conn HO. Esophageal tamponade in the treatment of bleeding varices. A decade progress report. Dig Dis Sci 1980; 25: 267-272

27 D'Amico M, Berzigotti A, Garcia-Pagan JC. Refractory acute variceal bleeding: what to do next? Clin Liver Dis 2010; 14: 297-305

28 Chong CF. Esophageal rupture due to Sengstaken-Blakemore tube misplacement. World J Gastroenterol 2005; 11: 6563-6565

29 Collyer TC, Dawson SE, Earl D. Acute upper airway obstruction due to displacement of a Sengstaken-Blakemore tube. Eur J Anaesthesiol 2008; 25: $341-342$

30 Rikkers $L F$. The changing spectrum of treatment for variceal bleeding. Ann Surg 1998; 228: 536-546

31 Willson PD, Kunkler R, Blair SD et al. Emergency oesophageal transection for uncontrolled variceal haemorrhage. Br J Surg 1994; 81: 992 995

32 Burroughs AK, Hamilton G, Phillips A et al. A comparison of sclerotherapy with staple transection of the esophagus for the emergency control of bleeding from esophageal varices. N Engl J Med 1989; 321: $857-862$

33 Huizinga WK, Angorn IB, Baker LW. Esophageal transection versus injection sclerotherapy in the management of bleeding esophageal varices in patients at high risk. Surg Gynecol Obstet 1985; 160: 539-546

34 Adam R, Diamond T, Bismuth H. Partial portocaval shunt: renaissance of an old concept. Surgery 1992; 111: 610-616

35 Darling RC3rd, Shah DM, Chang BB et al. Long-term follow-up of poorrisk patients undergoing small-diameter portocaval shunts. Am J Surg 1992; 164: 225-227; discussion 227-228

36 Boyer TD, Haskal ZJ. American Association for the Study of Liver Diseases. The role of transjugular intrahepatic portosystemic shunt in the management of portal hypertension. Hepatology 2005; 41: $386-$ 400

37 Sanyal AJ, Freedman AM, Shiffman ML et al. Portosystemic encephalopathy after transjugular intrahepatic portosystemic shunt: results of a prospective controlled study. Hepatology 1994; 20: 46-55

38 Hubmann R, Bodlaj G, Czompo M et al. The use of self-expanding metal stents to treat acute esophageal variceal bleeding. Endoscopy 2006; 38: $896-901$
39 Matull WR, Cross TJ, Yu D et al. A removable covered self-expanding metal stent for the management of Sengstaken-Blakemore tube-induced esophageal tear and variceal hemorrhage. Gastrointest Endosc 2008; 68: 767-768 (discussion 768)

40 Zehetner J, Shamiyeh A, Wayand $W$ et al. Results of a new method to stop acute bleeding from esophageal varices: implantation of a self-expanding stent. Surg Endosc 2008; 22: 2149-2152

41 Dechene A, Adamzik M, Gerken G et al. Acute bronchial obstruction following esophageal stent implantation for variceal bleeding. Endoscopy 2009; 41: E146-E147

42 Wright G, Lewis $H$, Hogan B et al. A self-expanding metal stent for complicated variceal hemorrhage: experience at a single center. Gastrointest Endosc 2010; $71: 71-78$

43 Mishin I, Ghidirim G, Dolghii A et al. Implantation of self-expanding metal stent in the treatment of severe bleeding from esophageal ulcer after endoscopic band ligation. Dis Esophagus 2010; 23: E35-E38

44 Dechêne A, El Fouly AH, Bechmann LP et al. Acute management of refractory variceal bleeding in liver cirrhosis by self-expanding metal stents. Digestion 2012; 85: 185-191

45 Holster IL, Kuipers EJ, van Buuren HR et al. Self-expandable metal stents as definitive treatment for esophageal variceal bleeding. Endoscopy 2013; 45: 485-488

46 Fierz FC, Kistler $W$, Stenz $V$ et al. Treatment of esophageal variceal hemorrhage with self-expanding metal stents as a rescue maneuver in a Swiss multicentric cohort. Case Rep Gastroenterol 2013; 7: 97 - 105

47 Zakaria MS, Hamza IM, Mohey MA et al. The first Egyptian experience using new self-expandable metal stents in acute esophageal variceal bleeding: pilot study. Saudi J Gastroenterol 2013; 19: 177-181

48 Maufa F, Al-Kawas FH. Role of self-expandable metal stents in acute variceal bleeding. Int J Hepatol 2012; 2012: 418369

49 Escorsell A, Bosch J. Self-expandable metal stents in the treatment of acute esophageal variceal bleeding. Gastroenterol Res Pract 2011; 2011: 910986

50 Seewald S, Mendoza G, Seitz $U$ et al. Variceal bleeding and portal hypertension: has there been any progress in the last 12 months? Endoscopy 2003; 35: 136-144

51 Sakai P, Maluf Filho F, Melo JM et al. Is endoscopic band ligation of esophageal varices contraindicated in Child-Pugh C patients? Endoscopy 1994; 26: $511-512$

52 Van Vlierberghe $H$, De Vos $M$, Hautekeete $M$ et al. Severe bleeding following endoscopic variceal ligation: should EVL be avoided in Child C patients? Acta Gastroenterol Belg 1999; 62: 175-177

53 Farivar AS, Vallières E, Kowdley KV et al. Airway obstruction complicating esophageal stent placement in two post-pneumonectomy patients. Ann Thorac Surg 2004; 78: e22 - e23

54 Libby ED, Fawaz R, Leano AM et al. Airway complication of expandable stents. Gastrointest Endosc 1999; 49: 136-137 